\title{
Carbohydrate Changes and Leaf Blackening in Cut Flower Stems of Protea eximia
}

\author{
R.L. Bieleski \\ Department of Scientific and Industrial Research Fruit and Trees, Auckland, New Zealand
}

\author{
J. Ripperda, J.P. Newman, and M.S. Reid \\ Department of Environmental Horticulture, University of California, Davis, CA 95616
}

Additional index words. polyol, polygalatol, senescence, postharvest, stress, sugars

\begin{abstract}
We tested the hypothesis that premature leaf blackening in cut flower stems of Protea eximia (Salisb. ex Knight) Fourcade may be brought about by a low leaf carbohydrate status. Leaves on cut flower stems held in darkness blackened within 4 days, whereas those on stems held in a greenhouse remained healthy for 5 days. Leaf blackening was also retarded by supplying $1 \%$ sucrose in the vase solution; but other additives (hypochlorite, silver thiosulfate, bisulfite) were not effective. The hypothesis was further explored by examining postharvest carbohydrate changes in the leaf of cut flower stems held in light or darkness. At harvest, leaves contained very little hexose $(<1$ $\mathrm{mg} \cdot \mathrm{g}^{-1}$ fresh weight), comparatively small concentrations of sucrose $\left(\approx 5 \mathrm{mg} \cdot \mathrm{g}^{-1}\right.$ fresh weight $)$ and $\mathrm{starch}\left(\approx 6 \mathrm{mg} \cdot \mathrm{g}^{-1}\right.$ fresh weight), but high concentrations $\left(\approx 30 \mathrm{mg} \cdot g-{ }^{1}\right.$ fresh weight) of the polyol polygalatol. Starch and sugar contents of leaves held in darkness fell rapidly, to one-third of their initial level after only 1 day and to one-sixth after 3 days. In contrast, starch and sugar contents increased slowly in leaves of stems held in light to three times the initial level after 3 days. Polygalatol content was unaffected by any treatment. Removal of the inflorescence did not delay blackening of leaves held in darkness and did not affect their carbohydrate changes.
\end{abstract}

A rapid blackening of the foliage is a commercially important postharvest problem with some species of Protea (Ferreira, 1983). Within a few days of harvest, the leaves become limp and leathery; a day or two later black areas develop, so that within 8 days of harvest most leaves can be completely black. The direct cause is a polymerization and oxidation of the abundant hydroxyphenols and tannins, occurring when cell compartmentation breaks down (Paull et al., 1980; Whitehead and de Swardt, 1982).

Several environmental stresses can potentially disrupt compartmentation in plant cells. These include chilling injury, anoxia, ethylene, water stress, and shortage of carbohydrates (Mayak and Halevy, 1980; Sacher, 1973). Until recently, postharvest blackening in Protea leaves was considered to be primarily a response to water stress (Paull et al., 1980; Whitehead and de Swardt, 1982). Evidence now appearing suggests that it may instead be due to depletion of leaf carbohydrate in the cut flower stem (Reid et al., 1989). Thus, leaf blackening was not affected by treatments reducing transpiration or increasing water stress, but was exacerbated when flowers were held in low-light conditions (Reid et al., 1989). Removal of the inflorescence (beheading) appeared to reduce leaf blackening, not by decreasing water loss (Paull et al., 1980), but by reducing the demand on the leaves for carbohydrate since girdling below the inflorescence had the same effect as removing it (Reid et al., 1989). The acceleration of leaf blackening at higher temperatures (Ferreira, 1986) could also result from an accelerated use of carbohydrate in respiration and metabolism.

To further test the role of carbohydrate status in the development of leaf blackening in Protea leaves, we have studied the effects of supplying exogenous sugar to the cut stems and the postharvest changes in endogenous leaf carbohydrates.

Received for publication 3 Dec. 1990. R.L.B. was supported by a DSIR New Zealand Prestige Study Award during the course of this work. We thank Dick La Rue, Santa Barbara, for supplying the flowers used; R.J. Redgwell for GLC measurements; H. Young for MS-FAB measurements; and A. Gunson for statistical analyses. The cost of publishing this paper was defrayed in part by the payment of page charges. Under postal regulations, this paper therefore must be hereby marked advertisement solely to indicate this fact.

\section{Materials and Methods}

Plant material. Flowering stems of Protea eximia were harvested at commercial maturity from fully grown plants in the Santa Barbara region of California, then used immediately for vase-solution experiments or cooled to $4 \mathrm{C}$ before being airfreighted to Davis, Calif. On unpacking within $24 \mathrm{~h}$ of harvest, stems were trimmed under water, then placed in $50 \mathrm{ppm}$ sodium hypochlorite in the greenhouse under full natural light $(=1300$ $\mu \mathrm{mol} \cdot \mathrm{m}^{-2} \cdot \mathrm{s}^{-1}$ at midday; $25 / 20 \mathrm{C}$ day/night) until used the following day. To confirm sugar patterns seen in the experimental material, leaves were taken directly from a growing plant and immediately analyzed for sugars.

Vase-1ife experiments. Flower stems, eight per treatment, in individual vases were given various treatments known to extend the vase life of other flowers: 1) pretreatment with $4 \mathrm{~mm}$ silver thiosulfate (STS), or 2) addition of $50 \mathrm{ppm} \mathrm{Na}$ hypochlorite, 3) $1 \mathrm{~mm} \mathrm{NaHSO}_{3}$, or 4$) 0.5 \%$ or $2 \%$ sucrose in $50 \mathrm{ppm}$ hypochlorite to the vase solution. A response to added sugar was further tested by supplying a range of sucrose concentrations $(0,0.2 \%, 0.5 \%$, and $1 \%$ in 50 ppm hypochlorite). Flower life was measured under standard vase-life conditions [20C, $60 \%$ relative humidity $(\mathrm{RH}), 12 \mathrm{~h}$ cool-white fluorescent light, $\approx 15$ $\mu \mathrm{mol} \cdot \mathrm{m}^{-2} \cdot \mathrm{s}^{-1}$ each day; Evans and Reid, 1988], its duration being scored as the time elapsed until $50 \%$ of leaf area had blackened. Each day, each leaf was inspected and a visual estimate was made of the proportion of its surface that was black (steps of 20\%), then the values for the 20 or so leaves were averaged to give a value for the stem.

Effects of light. Six replicate flower stems were placed in vases containing $50 \mathrm{ppm}$ hypochlorite (replaced each day) in the greenhouse under full natural light (light treatment) or in darkness (20C, 60\% RH; dark treatment) or darkness after first removing the inflorescence from the stem (beheaded treatment). The percentage of total leaf area that had blackened was recorded as above at 4 PM daily. In a preliminary study, the same protocol was used, except that there were only four stems per treatment and the effect of the inflorescence was modified by girdling instead of removal.

Changes in carbohydrate content. Standard tissue extraction 
methods resulted in problems with interfering polyphenols and with excess particulate matter that blocked columns and filters. The following procedure modified from Bieleski and Turner (1966) was satisfactory. Leaves on stems treated as above were sampled daily between 4 and 5 PM. Duplicate samples from each treatment contained six distal quarter-leaves, one from each of the six treated stems. When leaves began to blacken, black areas were excluded from the sample. Leaf pieces were cut with a razor blade into 8 to $15 \times 0.8$ to 1.2 -mm slices, mixed, and a 0.50 -g fresh-weight sample was frozen in liquid $\mathrm{N}_{2}$ then transferred to $10 \mathrm{ml}$ of 12 methanol :5 chloroform :3 water (MCW) (by volume) at $-25 \mathrm{C}$ and held at $-25 \mathrm{C}$ overnight. The $\mathrm{MCW}$ extract was transferred to a 30-ml centrifuge tube, and the residue was washed with $3 \mathrm{ml} \mathrm{MCW}$. (Tests showed that, because freezing. thin leaf slices in liquid $\mathrm{N}_{2}$ increased their penetration by MCW, $98.1 \%$ of total extractable sugar was removed in the MCW extract and wash, $1.8 \%$ was recovered in a subsequent aqueous $20 \%$ methanol extraction step, and $<0.1 \%$ more was recovered when the tissue was homogenized and further extracted in 20\% methanol, so that homogenizing the tissue was unnecessary). Chloroform $(3 \mathrm{ml})$ then water $(3 \mathrm{ml})$ were added to the combined MCW extract, causing the two phases to separate. The residue was extracted again with $5 \mathrm{ml}$ of $20 \%$ methanol and then stored at $-25 \mathrm{C}$ for subsequent starch estimation, while the methanol extract was added to the MCW and the mixture was centrifuged to split the phases. The chloroform layer was discarded, and the aqueous layer was taken to dryness in an air stream at 50C $(\approx 2 \mathrm{~h})$. The dried extract was redissolved in $2 \mathrm{ml}$ of water, then cations and anion's were removed using 1.5-ml columns of Biorex $70(\mathrm{H}+)$ then Biorex $5(\mathrm{OH}-)$. The eluate was reduced to $5.0 \mathrm{ml}$ in an air stream as before, and an aliquot was filtered through a $0.22-\mu \mathrm{m}$ cellulose acetate membrane filter to remove particulate. Sugars were separated and quantified by high-performance liquid chromatography (HPLC) using a Hewlett-Packard 1084B (Aminex HPX 87C column, $85 \mathrm{C}$, water solvent) equipped with a refractive index detector (Altex; Beckman Instruments).

Estimation of starch. Conventional procedures (Evans and Reid, 1988) were modified to suit the experimental material. Direct amyloglucosidase (EC 3.2.1.3) treatment of the nonhomogenized slices was found to be effective, with less variability and slightly higher starch yield than was obtained by treatment after homogenizing the tissue. Use of a much lower buffer concentration $(\approx 1 \mathrm{mM})$ than is usual $(\approx 100 \mathrm{mM})$ caused no problems with $\mathrm{pH}$ control and allowed the reaction products to be directly assayed by HPLC without preliminary deionization. Thus, following sugar extraction, the samples were dried (70C, 30 rein) to remove methanol and chloroform, then dehydrated with $4 \mathrm{ml}$ of water plus $4 \mathrm{mg}$ of inositol as internal standard. The vials were heated three times $(15,15,30$ rein) in a boiling water bath, with cooling between each heating step to completely rewet the dried tissue and gelatinize the starch. Buffer $(100 \mu \mathrm{l} 2 \mathrm{~mm}$ potassium succinate buffer, $\mathrm{pH}$ 4.6) and insoluble, enzymegrade polyvinylpyrrolidone (50 mg PVP) were added, and the tubes were shaken for $15 \mathrm{~min}$ to allow adsorption of phenols to the PVP. The tubes were then incubated for $18 \mathrm{~h}$ (shaking water bath, 55C) with 200 pd amyloglucosidase (Sigma, ex Rhizopus, 20 units/ml in $0.5 \mathrm{~mm} \mathrm{~K}$ succinate, brought to $\mathrm{pH} 4.6$ ) to hydrolyze starch to glucose. After heating at $100 \mathrm{C}$ for $5 \mathrm{~min}$ to denature the enzyme, the liquid volume was brought to $5.0 \mathrm{ml}$ with water. A $2.0-\mathrm{ml}$ aliquot of the digestion mix was centrifuged at $13,000 \times \mathrm{g}$ for 15 rein, filtered through a $0.22-\mu \mathrm{m}$ cellulose acetate filter to remove particulate matter, and directly assayed for free glucose by HPLC as above. The efficiency of the assay was estimated by adding starch to parallel samples: recoveries were in the range of $73 \%$ to $81 \%$, so sample values were corrected by $1.30 \times$.

Thin-layer chromatography (TLC). Identity of compounds, and in particular of a major sugar component eventually identified as polygalatol (Plouvier, 1964), was tested by TLC [Supelco Redi-coat G silica gel, using 11 n-propyl acetate :5 formic acid : 3 water (by volume)] using various detection reagents (Dawson et al., 1969) and by GLC (acetyl derivatives, SP 2330 column).

\section{Results}

Effects of vase solution additives. Leaf blackening in cut flower stems of P. eximia was substantially delayed by the addition of $0.5 \%$ sucrose plus hypochlorite to the vase solution, but not by additives that reduced a bacterial contamination of the stems (hypochlorite) or the effects of ethylene (STS) (Table 1); $0.5 \%$ and $1 \%$ sucrose also delayed typical blackening (Table 2), but $2 \%$ sucrose caused a type of black spotting that made the leaves unsightly while not covering a large total area.

Carbohydrate pattern in the leaves. Seven carbohydrate fractions were isolated in soluble carbohydrate extracts from newly harvested P. eximia leaves and in leaves of the experimental material received in Davis ( $\mathrm{mg} \cdot \mathrm{g}^{-1}$ fresh weight): sucrose (46 ), inositol $(\approx 1)$, glucose $(\approx 0.3)$, fructose $(\approx 0.1)$, raffinose or a similar trisaccharide $(0.1)$, and oligosaccharide $(\approx 2)$ plus a major unknown compound (25-30). Initial investigations indicated that it was a polyol, although not one of the common ones with available standards. It was subsequently purified and crystallized to provide a standard and shown by mass spectrometry using fast-atom bombardment (MS-FAB) to be polygalatol, as previously reported for Protea spp. (Boeyens et al., 1983; Plouvier, 1964).

Table 1, Effect of chemical pretreatment and vase solution additives on leaf blackening in Protea eximia under flower evaluation room conditions.

\begin{tabular}{lc}
\hline \hline Treatment & $\begin{array}{c}\text { Vase life } \\
\text { (days) }\end{array}$ \\
\hline Control & $9.4 \mathrm{bc}$ \\
$4 \mathrm{mM} \mathrm{STS}$ pretreatment & $8.2 \mathrm{bc}$ \\
$50 \mathrm{ppm} \mathrm{Na}$ hypochlorite & $8.3 \mathrm{bc}$ \\
$1 \mathrm{mM} \mathrm{NaHSO}$ & $7.2 \mathrm{c}$ \\
$0.5 \%$ Sucrose $+50 \mathrm{ppm}$ hypochlorite & $16.0 \mathrm{a}$ \\
$2 \%$ sucrose $+50 \mathrm{ppm}$ hypochlorite & $13.8 \mathrm{a}$ \\
\hline
\end{tabular}

${ }^{2}$ Data (means of eight replicates) are expressed as mean days to $50 \%$ of leaf area blackened; mean separation by Duncan's multiple range test $(P<0.01)$.

Table 2. Effect of sucrose concentration in the vase solution on leaf blackening in Protea eximia under flower evaluation room conditions. ${ }^{z}$,

\begin{tabular}{lr}
\hline \hline $\begin{array}{l}\text { Sucrose concn } \\
(\%)\end{array}$ & $\begin{array}{c}\text { Vase life } \\
\text { (days) }\end{array}$ \\
\hline 0 & $7.3 \mathrm{a}$ \\
0.2 & $7.9 \mathrm{a}$ \\
0.5 & $12.8 \mathrm{~b}$ \\
1 & $14.0 \mathrm{~b}$ \\
\hline \hline
\end{tabular}

${ }^{2} \bar{D}$ ata (means of 10 replicates) are expressed as mean days to $50 \%$ of leaf area blackened; mean separation by Duncan's multiple range test $(P<0.01)$.

${ }^{y}$ All solutions contained $50 \mathrm{ppm}$ Na hypochlorite. 
Effect of light on leaf blackening and carbohydrate content. Under light conditions in the greenhouse, leaves of the stems in light remained stiff and sustained very little blackening over the 5 days of the experiment (Fig. 1A). By contrast, leaves of the stems in darkness or of those beheaded became limp within 3 days, and by day 4, there was extensive leaf blackening (Fig. 1A). By day 5, all leaves in darkness contained some black areas, and it became difficult to obtain samples of undamaged tissue for carbohydrate analysis.

In the greenhouse, the starch content of the leaves rose steadily from $\approx 2.5 \mathrm{mg} \cdot \mathrm{g}^{-1}$ fresh weight, reaching a plateau at $\approx 14$ $\mathrm{mg} \cdot \mathrm{g}^{-1}$ fresh weight after 3 days (Fig. lB). Sucrose content rose also, to $7 \mathrm{mg} \cdot \mathrm{g}^{-1}$ fresh weight (Fig. 1C). In marked contrast, in both the dark and beheaded treatments, the starch and sucrose contents fell rapidly over the first 1 to 2 days, reaching a constant level after the 3rd day at $\approx 0.5$ and $0.9 \mathrm{mg} \cdot \mathrm{g}^{-1}$ fresh weight, respectively. Concentrations of polygalatol remained relatively steady throughout the experiment, regardless of treatment or extent of leaf blackening (Fig. 1B). Amounts of glucose, fructose, inositol, raffinose, and oligosaccharide did not change appreciably. Thus, in light, which resulted in negligible leaf blackening, leaf photosynthetic capacity exceeded demand, so that the amount of storage carbohydrates, starch plus sucrose, increased 3 -fold over 3 days, to $19 \mathrm{mg} \cdot \mathrm{g}^{-1}$ fresh weight. In darkness, the opposite was the case, and the presumed metabolizable carbohydrate pools were fully depleted within 3 days, the initial loss rate being $\approx 5 \mathrm{mg} / \mathrm{g}$ fresh weight per day. Virtually identical results regarding the contents of sucrose, polygalatol, and other sugars and the effect of girdling were obtained in the preliminary experiment (data available on request).

\section{Discussion}

The changes reported here in carbohydrate content of leaves from cut flower stems of $P$. eximia held in light or darkness are consistent with our hypothesis that the leaf-blackening disorder arises out of a depletion of leaf carbohydrate. Leaf blackening was visible shortly after the starch and sugar content of the leaves had fallen to their minimum level. A small proportion of the sucrose plus starch pool, totaling $1.4 \mathrm{mg}$ carbohydrate/g
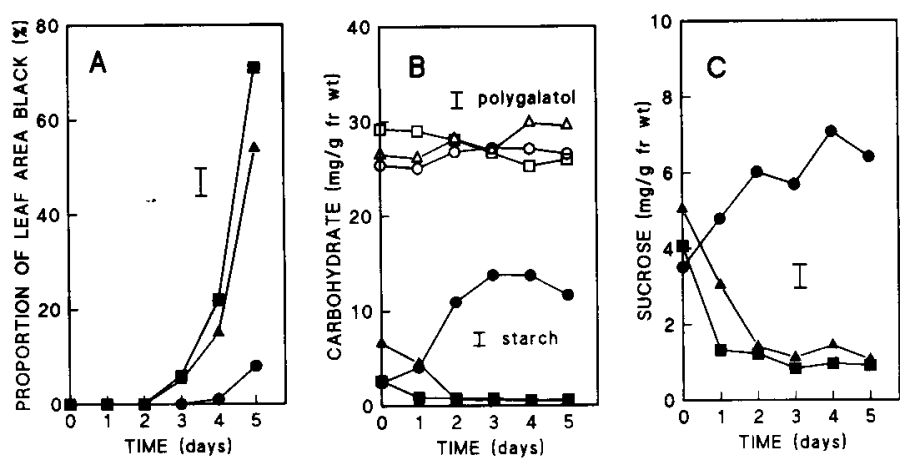

Fig. 1. Changes with time in leaf blackening and leaf carbohydrate content in Protea eximia as affected by various treatments. Plants in light $(\bullet, 0)$, in darkness $(\boldsymbol{\square}, \square)$, and beheaded $(\boldsymbol{\Delta}, \Delta)$. (A) Leaf blackening as a percentage of total leaf area. (B) Starch content (solid" symbols) and polygalatol content (open symbols). (C) Sucrose content. Each point is the mean of two values from duplicate tissue samples, the bars give the $\mathbf{S E}$ of means from analysis of variance. Starch data showed a skewed distribution, so a logarithmic transformation was performed before statistical analysis, giving means: light, 2.066; dark, - 0.146; beheaded, 0.160; and SE of means, 0.2243 fresh weight, could not be accessed for metabolism, as neither metabolize was totally used, even after 5 days when the leaf tissues were at the point of death. This conserved portion is $\approx 20 \%$ of the amount available in the leaf at the start of the experiment and $\approx 7 \%$ of the amount present in leaves loaded under the light conditions of the greenhouse.

Reid et al. (1989) have reported that beheading and girdling of Protea flower stems retarded leaf blackening and proposed that a reduced carbohydrate demand on the leaves was the cause. In our present experiments, neither the rate of blackening nor carbohydrate loss was reduced by the above treatments. The differing results may have arisen because our beheaded stems were in total darkness, whereas the other studies were made under vase-life room conditions with enough light to trigger physiological phenomena (Evans and Reid, 1988) and, perhaps, allow some. photosynthesis to occur. Also the carbohydrate status of the stems at the start of the experiment could have affected the response to girdling or beheading.

If loss of carbohydrate from the leaves is the cause of leaf blackening, provision of sucrose in the vase solution should help overcome the disorder. Brink and de Swardt (1986) showed that $0.2 \%$ to $1 \%$ sucrose retarded the onset of leaf blackening in $P$. neriiifolia, but that $3 \%$ sucrose was deleterious. We observed a similar effect in P. eximia. We can now compare endogenous changes with what might be supplied in a vase solution. Leaves on a flowering branch of $P$. eximia have a fresh weight of $\approx 120$ to $200 \mathrm{~g}$. A carbohydrate depletion rate of $\approx 5 \mathrm{mg} / \mathrm{g}$ fresh weight per day, deduced above, would result in a total loss in darkness of $\approx 600$ to $1000 \mathrm{mg}$ (starch + sucrose) per day. A P. eximia flower stem takes up $70 \mathrm{ml}$ of pulsing solution per day under experimental conditions (Brink and de Swardt, 1986; Paull et al., 1980); a 1'\% sucrose solution will, therefore, supply 700 $\mathrm{mg} \cdot$ day ${ }^{-1}$ close to the total amount being used. It seems likely that most or all of the carbohydrate depleted in darkness is used in respiration. Assuming sucrose as the respiratory substrate, respiration in $P$. eximia flower stems, if the same as in $P$. neriifolia $(\approx 180 \mathrm{ml} 02 / \mathrm{kg}$ fresh weight per hour at $25 \mathrm{C}$; Ferreira, 1986), would require $5.5 \mathrm{mg}$ sucrose/g fresh weight per day-much the same as the measured rate of loss.

The $2 \%$ sucrose solution would potentially supply sugar at two times the rate required, and the oversupply could explain why leaf spotting results from its use. Spotting is absent when the oversupply of carbohydrate arises from endogenous production under high-light conditions. Possibly, the different sources lead to carbohydrate accumulating in different cell compartments or tissues. In theory, placing the harvested flowers for 2 days under high light should increase the usable carbohydrate supply 2.5 times, extending the potential survival time in darkness to $\approx 10$ instead of 4 days. These findings suggest further experimental manipulations and strategies for improving storage life of flowers.

Features of the carbohydrate pattern itself in Protea are the relatively low levels of sucrose and starch, as well as the high concentration of polygalatol and its complete unavailability for remetabolism. Had it been fully accessible, it could have doubled the survival time in the dark. Because the polyol fraction is not used, osmotic changes in the cell due to carbohydrate depletion in the dark, or from oversupply of exogenous sucrose, are unlikely to be the cause of loss of membrane function, in that the osmotic behavior should be dominated by the polyol in all those situations. Indeed, this osmotic buffering by inert polyol may be part of the adaptation of many of the Protea species to a dry habitat (Bieleski, 1982). While the polyol would thus protect against rapid desic- 
cation under natural growth conditions, its unavailability as a carbohydrate supply appears to contribute to the rapid death of the leaves of harvested Protea flower stems.

\section{Literature Cited}

Bieleski, R.L. 1982. Sugar alcohols, p. 158-192. In: A. Loewus and W. Tanner (eds.). Plant carbohydrates I. Intracellular carbohydrates. Encyclopedia of Plant Physiology, NS vol. 13A. Springer-Verlag, Berlin.

Bieleski, R.L. and N.A. Turner. 1966. Separation and estimation of amino acids in crude plant extracts by thin-layer electrophoresis and chromatography. Anal. Biochem. 17:278-293.

Boeyens, J.C.A., J.L.C. Marais, and G.W. Perold. 1983. The occurrence, conformation and crystal structure of 1,5-anhydro-D-glucitol in Protea spp. Photochemistry 22:1959-1960.

Brink, J.A. and G.H. de Swardt. 1986. The effect of sucrose in a vase solution on leaf browning of Protea neriifolia R. Br. Acta Hort. 185:111-119.

Dawson, R.M.C., D.C. Elliot, W.H. Elliot, and K.M. Jones. 1969. Data for biochemical research. 2nd ed. Oxford University Press, Oxford, U.K.

Evans, R.Y. and M.S. Reid. 1988. Changes in carbohydrates and osmotic potential during rhythmic expansion of rose petals. J. Amer. Soc. Hort. Sci. 113:884-888.

Ferreira, D.I. 1983. Prevention of browning of leaves of Protea neriifolia R. Br. Acta Hort. 138:273-276.

Ferreira, D.L 1986. The influence of temperature on the respiration rate and browning of Protea neriifolia R. Br. inflorescences. Acta Hort. 185:121-129.

Mayak, S. and A.H. Halevy. 1980. Flower senescence, p. 131-156. In: K.V. Thimann (ed.). Senescence in plants. CRC Press, Boca Raton, Fla.

Paull, R., R.A. Criley, T. Goo, and P.E. Parvin. 1980. Leaf blackening in cut Protea eximia: Importance of water relations. Acta Hort. 113:159-166.

Plouvier, V. 1964. Sur la recherche des polyalcools et des heterosides cyanogenetiques chez quelques Proteacees. Comptes rendus Acad. Sci. 259:665-668.

Reid, M. S., W. van Doom, and J.P. Newman. 1989. Leaf blackening in Proteas. Acta Hort. 261:81-84.

Sacher, J.A. 1973. Senescence and postharvest physiology. Annu. Rev. Plant Physiol. 24:197-224.

Whitehead, C.S. and G.H. de Swardt. 1982. Extraction and activity of polyphenoloxidase and peroxidase from senescing leaves of Protea neriifolia. S. Afr. J. Bot. 1:127-130. 